\title{
Prevalence of Metabolic Syndrome in Non-Obese Newly Detected Type 2 Diabetes Mellitus
}

\author{
Mahbooba Akhter ${ }^{1}$, Afsana Ahmed ${ }^{2}$, Mahbubor Rahman $^{3}$, Roksana Malek ${ }^{4}$, Azmeri Alam ${ }^{5}$ Mozammel Hoque ${ }^{6}$ \\ ${ }^{1}$ Lecturer, Department of Biochemistry, Dhaka Medical College, ${ }^{2}$ Associate Professor, Department of Biochemistry, Dhaka National Medical College, \\ ${ }^{3}$ MD Final part student, Internal Medicine, Department of Medicine, Dhaka Medical College, ${ }^{4}$ Lecturer, Department of Biochemistry, Sir Salimullah \\ Medical College, ${ }^{5}$ Associate Professor Department of Biochemistry, Green Life Medical College, ${ }^{6}$ Professor and Chairman, Department of Biochemis- \\ try, Bangabandhu Sheikh Mujib Medical University.
}

\begin{abstract}
:
Background: The metabolic syndrome is driving twin global epidemics; type 2 diabetes mellitus and cardiovascular disease. There is an overwhelming moral, medical, and economic imperative to identify those individuals with metabolic syndrome. Regarding this issue, non obese individuals are given less attention and ultimately situation becomes grievous theref ore. Objective: To assess the prevalence of metabolic syndrome in non-obese newly detected type 2 DM patient. Method: This cross sectional analytical study was carried out in the department of Biochemistry, Bangabandhu Sheikh Mujib Medical University, Dhaka, Bangladesh. Total 209 cases (165 male \& 44 f emale) were selected from BIRDEM. Statistical analysis and data management were carried out using the SPSS (Version 12.0). Result: In this study, prevalence rates of metabolic syndrome were $60.3 \%$ (53.3\% male, $86.4 \%$ f emale), $58.9 \%$ (57.0\% male, $65.9 \% \mathrm{f}$ emale) and $26.3 \%$ (15.8\% male, $65.9 \% \mathrm{f}$ emale) according to modif ied National Cholesterol Education Program Adult Treatment Panel III (NCEP-ATP III), modif ied WHO \& IDF criteria respectively. Conclusion: Prevalence of metabolic syndrome in non-obese newly detected Type 2 DM is very high \& Prevalence of metabolic syndrome in non-obese newly detected Type $2 \mathrm{DM} f$ ound signif icantly higher in $\mathrm{f}$ emale than male. Adequate realistic steps of preventive strategy are of urgent need to combat this high prevalence of metabolic syndrome in non-obese diabetic people.
\end{abstract}

Key words: Diabetes; Metabolic syndrome; Non-obese

[BSMMUJ $2016 ; 9$ (1) : 26-31]

\section{Introduction:}

A cluster of risk factors for cardiovascular disease and type 2 diabetes mellitus which occur together more often than by chance alone is known as the metabolic syndrome (MS). The risk factors include raised blood pressure, dyslipidemia (raised triglycerides and lowered high density lipoprotein cholesterol), raised fasting blood glucose and central obesity'.

According to International Diabetes Federation (IDF) the

Corresponding Author: Dr. Mahbooba Akhter,Lecturer, Department of Biochemistry, Dhaka Medical College, Dhaka.

e-mail : mahbooba_akhter@yahoo.com metabolic syndrome is driving twin global epidemics; type 2 diabetes mellitus \& cardiovascular disease. ${ }^{2}$ According to Third National Health and Nutrition Examination Survey (NHANES III) data, people who did not have metabolic syndrome had the lowest risk for coronary heart disease events, those with metabolic syndrome had an intermediate level of risk, and those with diabetes had the highest level of risk ${ }^{3}$.

The metabolic syndrome which appears to be the antecedent or "common soil" for both diabetes \& coronary heart disease is also common among South Asians. South Asians develop metabolic abnormalities at a lower body mass index and waist circumference than other groups, so 
conventional criteria to estimate the prevalence of metabolic syndrome is $25 \%$ to $50 \%$ less than the expected rate.

The prevalence of metabolic syndrome was high among the type 2 DM subjects which was observed $76.3 \%$, $37.5 \%$ and $76.3 \%$ according to modified National Cholesterol Education Program Adult Treatment Panel III (NCEP-ATP III), International Diabetes Federation (IDF) \& World Health Organization (WHO) respectively ${ }^{5}$. In a rural community in Bangladesh prevalence of metabolic syndrome was found to be $20.7 \%, 11.2 \%$ \& $8.6 \%$ following modified ATP, IDF \& WHO classification. In that study, highest prevalence rates for both sexes were found in ATP III criteria \& women showed higher occurrence according to all three classifications. Surprisingly prevalence of metabolic syndrome was found about 4 times more in type $2 \mathrm{DM}$ patients than overall in those study subjects $(76.3 \%, 37.5 \% \& 76.3 \%)$ according to modified ATP III, IDF \& WHO respectively ${ }^{5}$.

Obesity itself has so far been accepted to some people as an alarming sign of cardio metabolic risk factor; non obese individuals are reluctant about this issue but they may potentially display a cluster of obesity related features. Because of its high prevalence the risk associated with the presence of metabolic syndrome is receiving attention. Unfortunately non obese individuals are given less attention \& ultimately situation become grievous.

Therefore it is important to explore the status of metabolic syndrome in non-obese individuals as well. The existence and prevalence of metabolic syndrome in non-obese newly detected type 2 DM individuals has not been systematically investigated. So in this study we have made an attempt to evaluate the prevalence of metabolic syndrome in non-obese newly detected type $2 \mathrm{DM}$.

\section{Methods:}

This cross sectional analytical study was carried out in the Department of Biochemistry, Bangabandhu Sheikh Mujib Medical University (BSMMU), Dhaka, from July 2008 to June 2009. 209 (165 male \& 44 female) non-obese (with

\section{Table-I}

Metabolic syndrome was defined by the criteria?

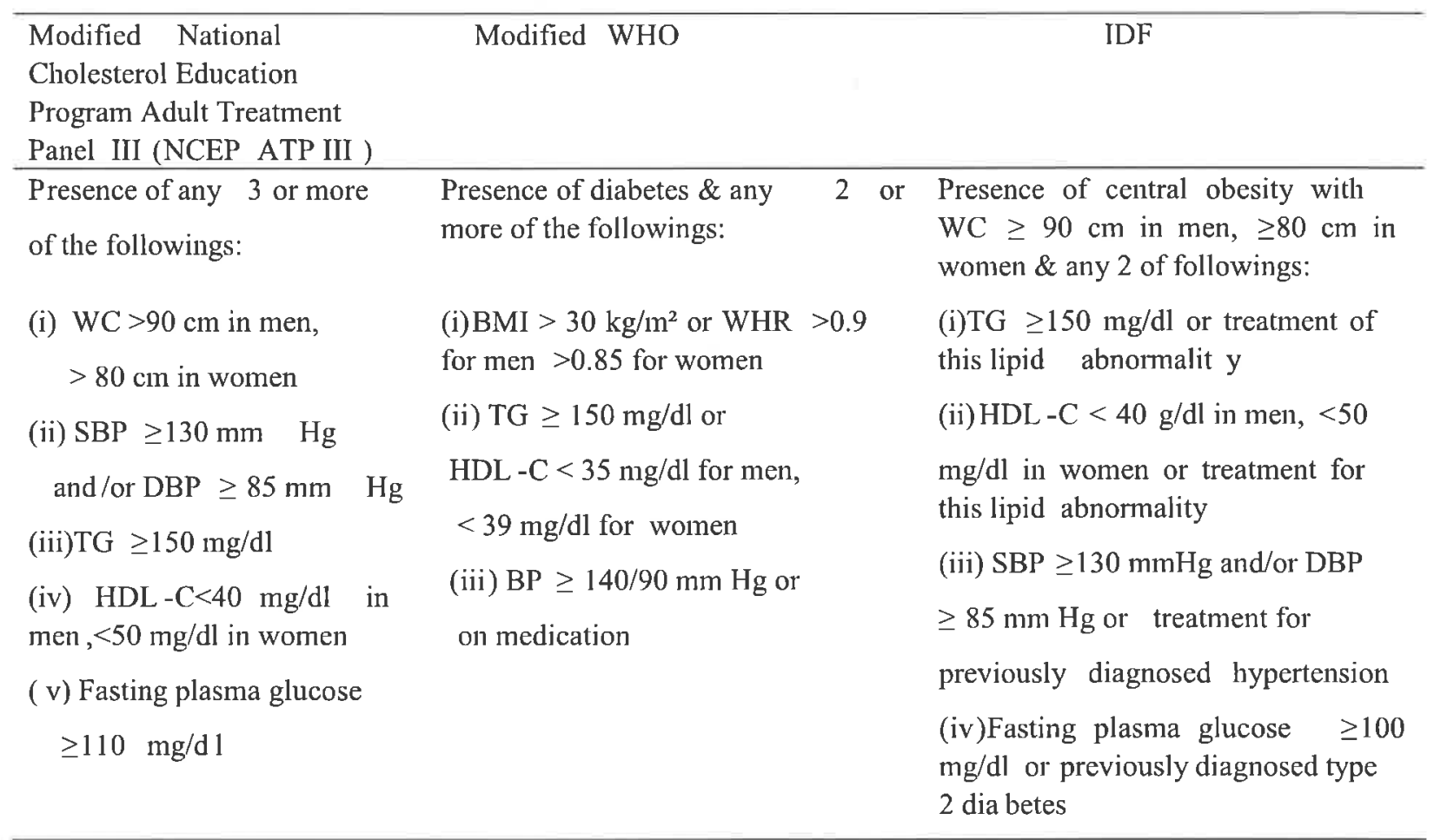


BMI $\left.<25 \mathrm{~kg} / \mathrm{m}^{2}\right) 6$ newly detected type 2 DM patients (diabetes detected within 6 months) were selected from BIRDEM.

Blood pressure, height, weight, waist $\&$ hip circumference were measured.BMI \& waist-hip ratio (WHR) was calculated. All relevant biochemical parameters i.e. Low density lipoprotein- cholesterol (LDL-C), High density lipoprotein-cholesterol (HDL-C), Triglyceride (TG) were measured using standard technique. Results were reported as the mean $\pm \mathrm{SD} \&$ percentage. The Prevalence of metabolic syndrome was estimated by calculating the percentages at 95\% CI. Proportion test used for comparison of the prevalence of metabolic syndrome between male \& female. $p<0.05$ was taken as the level of significance. Kappa test was done to examine the agreement between prevalence evaluated by using modified NCEP-ATP III, modified WHO \& IDF criteria.

\section{Result:}

In this study, we have found 126 (88 male, 38 female) individuals out of 209 (165 male, 44 female) study subjects to have metabolic syndrome according to modified NCEP-ATP III criteria. Using modified WHO \& IDF criteria 123 (94 male, 29 female) \& 55 (male 26, female 29 ) individuals were detected to have metabolic syndrome respectively.

\section{Table -II}

Frequency of Metabolic syndrome among the study subjects

\begin{tabular}{llll}
\hline Criteria of MS & Total Popu & Male & Female \\
& $\begin{array}{l}\text { lation } \\
(\mathrm{n}=209)\end{array}$ & $(\mathrm{n}=165)$ & $(\mathrm{n}=44)$ \\
& & \\
\hline
\end{tabular}

\section{Modified}

\begin{tabular}{llll} 
NCEP ATP- III & 126 & 88 & 38 \\
Modified WHO & 123 & 94 & 29 \\
IDF & 55 & 26 & 29 \\
\hline
\end{tabular}

Table - III

Prevalence of metabolic syndrome in study' subjects.

\section{Criteria of}

metabolic syndrome

Total population

(n $=209)$

Prevalence

$\begin{array}{ll}\text { Modified NCEP-ATP III } & 60.3 \% \\ \text { Modified WHO } & 58.9 \% \\ \text { IDF } & 26.3 \%\end{array}$

Table IV shows comparison of the prevalence of metabolic syndrome between male \& female diagnosed according to modified NCEP-ATP III, modified WHO \& IDF criteria. Proportion test was done as the test of significance. Prevalence of metabolic syndrome in female found significantly higher compared to male according to modified NCEP-ATP III \& IDF criteria, but with respect to modified WHO criteria, prevalence of metabolic syndrome between male \& female did not differ significantly.

\section{Table -IV}

Comparison of the prevalence of metabolic syndrome between male \& female

\begin{tabular}{llll}
\hline $\begin{array}{l}\text { Criteria of } \\
\text { metabolic syndrome }\end{array}$ & $\begin{array}{l}\text { Male } \\
(\mathrm{n}=165)\end{array}$ & $\begin{array}{l}\text { Female } \\
(\mathrm{n}=44)\end{array}$ & P-value \\
\hline Modified & & & \\
NCEP ATP- III & $53.3 \%$ & $86.4 \%$ & $<0.05$ \\
Modified WHO & $57.0 \%$ & $65.9 \%$ & $>0.05$ \\
IDF & $15.8 \%$ & $65.9 \%$ & $<0.05$ \\
\hline
\end{tabular}

Fair agreement observed between modified NCEP ATP III \& modified WHO criteria $(\mathrm{k}=0.50)$, slight agreement observed between modified WHO \& IDF $(\mathrm{k}=0.30)$ and IDF \& modified NCEP-ATP III criteria $(\mathrm{k}=0.36)$ in detection of metabolic syndrome (Table V). 
Table - V

Agreement between modified NCEP-ATP III \& modified WHO, modified WHO \& IDF and

$I D F \&$ modified NCEP-ATP III criteria with respect to the detection of metabolic syndrome

\begin{tabular}{|c|c|c|c|c|c|}
\hline Criteria & & & & & Kappa (k) \\
\hline \multirow{3}{*}{$\underbrace{0}_{i=0}$} & & Modified NCEP & -ATP III & & \multirow{3}{*}{$\begin{array}{l}0.50 \\
\text { (Fair agreement) }\end{array}$} \\
\hline & MS Present & $\begin{array}{c}\text { MS present } \\
99\end{array}$ & $\begin{array}{l}\text { MS absent } \\
24\end{array}$ & $\begin{array}{c}\text { Total } \\
123\end{array}$ & \\
\hline & $\begin{array}{l}\text { MS Absent } \\
\text { Total }\end{array}$ & $\begin{array}{c}27 \\
126\end{array}$ & $\begin{array}{l}59 \\
83\end{array}$ & $\begin{array}{r}86 \\
209\end{array}$ & \\
\hline \multirow[t]{3}{*}{ 息 } & MS present & $\begin{array}{l}\text { Modified WHO } \\
\text { MS present } \\
\quad 49\end{array}$ & $\begin{array}{c}\text { MS absent } \\
06\end{array}$ & $\begin{array}{c}\text { Total } \\
55\end{array}$ & \multirow{3}{*}{$\begin{array}{c}0.30 \\
\text { (Slight agreement) }\end{array}$} \\
\hline & MS absent & 74 & 80 & 154 & \\
\hline & Total & 123 & 86 & 209 & \\
\hline 总司 & $\begin{array}{l}\text { MS present } \\
\text { MS absent } \\
\text { Total }\end{array}$ & $\begin{array}{cr} & \text { IDF } \\
\text { MS } & \text { present } \\
& \\
54 \\
01 \\
55 \\
\end{array}$ & $\begin{array}{r}72 \\
82 \\
154 \\
\end{array}$ & $\begin{array}{r}\text { Total } \\
126 \\
83 \\
209 \\
\end{array}$ & $\begin{array}{l}0.36 \\
\text { (Slight agreement) }\end{array}$ \\
\hline
\end{tabular}

\section{Discussion:}

In this study, diversity of prevalence of metabolic syndrome observed. The prevalence rates are $60.3 \%$ (53.3\% male, $86.4 \%$ female), $58.9 \%$ ( $57.0 \%$ male, $65.9 \%$ female) and $26.3 \%$ (15.8\% male, $65.9 \%$ female) according to modified NCEP-ATP III, modified WHO and IDF criteria respectively. This is supported by Dhanaraj et $\mathrm{al}^{3}$, where prevalence rate of metabolic syndrome observed $67.9 \% \& 64.5 \%$ in newly detected type 2 diabetes in Indian population according to modified NCEP-ATP III \& modified WHO respectively.

Findings of this study is in agreement with prevalence rate measured by Rahim et al.5 in Bangladeshi rural population with type $2 \mathrm{DM}$, they found the prevalence rate of metabolic syndrome to be $76.3 \%, 76.3 \%$ \& $37.5 \%$ according to modified NCEP-ATP III, modified WHO \& IDF criteria respectively. In this study prevalence rate of metabolic syndrome diagnosed by IDF criteria showed lower value $(26.3 \%)$; probably due to the fact that our study subjects were strictly non-obese, whereas central obesity (increased waist circumference) is a mandatory criterion to diagnose metabolic syndrome by IDF guideline.

The findings of our study found similar to those among diabetic subjects according to NCEP-ATP criteria reported in the United Kingdom Prospective Diabetes
Study (UKPDS-2007). The reported prevalence of MS found to be $61 \%$ in that study and according to WHO and IDF criteria, $38 \%$ and $54 \%$ respectively ${ }^{8}$. Our study reported very high prevalence of metabolic syndrome. This is a unique finding and shows type 2 diabetes subjects have high cardiovascular risk as observed in British and Americans. This further explicit that individuals with diabetes have more cardiovascular risk factors as compared to those without diabetes and generalized obesity does not play important role. In this study, all of our study subjects are diabetic; so higher prevalence rate of metabolic syndrome in our study may be due to sharing of some common factors in this diabetic population. In abroad prevalence rate of metabolic syndrome found to be high in diabetic patients which is observed as $77 \%$ \& $65 \%$ (Mahadik, Deo \& Mahatalia9,Janghorbani \& Amini10). By gender, $53.3 \%$ male versus $86.4 \%$ female, $57.0 \%$ male versus $65.9 \%$ female \& $15.8 \%$ male versus $65.9 \%$ female prevalence rate of metabolic syndrome are observed using modified NCEP-ATP III, modified WHO \& IDF criteria in this present study. This is supported by Mahadik,Deo \& Mehatalia ${ }^{9}$, A1-Shafee et al11 and Malik \& Rajig12; They found prevalence rate of metabolic syndrome to be $12 \%$ male versus $18 \%$ female, $30.8 \%$ male versus $58.9 \%$ female \& $34.8 \%$ male, $48.4 \%$ female respectively. In our study, high prevalence of metabolic syndrome in female can be attributed to prevailing social and cultural factors that promote sedentary lifestyles and physical inactivity. 
Women in this region spend a large part of their time in the home and have little access to sports and other physical activities. As far as the Asian race is concerned, there could be some genetic factors involved that make women to be more prone to develop metabolic syndrome.

Among the three criteria used for the detection of metabolic syndrome in this study, higher prevalence rate is detected by modified NCEP-ATP III criteria. The possible foremost reason for higher prevalence rates of metabolic syndrome following modified NECP-ATP III appeared to be its inclusion of flexible Waist Circumference for the Asian subjects and use of new cut-off for fasting blood glucose threshold. The IDF and modified NCEP-ATP III definitions use the same five components and their defined cut-off values are also identical other than "central obesity" which is required as a core component in the IDF classification. In contrast, the modified NCEPATP III definition requires central obesity as one of the five equally weighted components for the required definition.

In this study, fair agreement observed between modified NCEP ATP III \& modified WHO criteria $(\mathrm{k}=0.50)$, slight agreement observed between modified WHO \& IDF $(\mathrm{k}=0.30)$ and IDF \& modified NCEP-ATP III $(\mathrm{k}=0.36)$ criteria in detection of metabolic syndrome. This is supported by Li \& Ford 13 and Rahim et $\mathrm{al}^{5}$, where they showed fair agreement $(\mathrm{k}=0.56 \& \mathrm{k}=0.45$ respectively) between NCEP-ATP and WHO criteria.

The findings of our study suggest that modified NCEPATP III \& modified WHO criteria are superior to IDF criteria in identifying metabolic syndrome in non-obese known to have type 2 DM. From the agreement test (Kappa) done between modified NCEP-ATP III \& modified WHO, IDF \& modified NCEP-ATP III and modified WHO \& IDF criteria, it is observed that the existing IDF criteria is not suitable in diagnosing metabolic syndrome in non-obese newly detected type 2 diabetes mellitus patient.

\section{Conclusion:}

From this study it can be concluded that prevalence of metabolic syndrome in non-obese newly detected Type 2 diabetes mellitus is very high. It is also observed that prevalence of metabolic syndrome is significantly higher in female than male in that diabetic population. The findings of this study suggest that modified NCEP-ATP III criteria is more applicable in defining metabolic syndrome in patients known to have type 2 diabetes mellitus.

In spite of some limitations, we are optimistic that conclusions derived from this study at least has given some awareness of this important but overlooked health issue $\&$ has created a window to visualize \& conceptualize the magnitude of this health issue $\&$ to get into it. We hope that this study will stimulates \& facilitates further large-scale population based studies to identify the extent of the problem \& assessment of its predictors which is essential for intervention to reduce this alarming issue.

\section{References:}

01. Alberti KG, Eckel RH, Grundy SM, Zimmet PZ, Cleeman JI, Donato KA et al. Harmonizing the metabolic syndrome: a joint interim statement of the Internatioual Diabetes Federation Task Force on Epidemiology and Prevention: National Heart, Lung, and Blood Institute; American Heart Association; World Heart Federation; International Atherosclerosis Society; and International Association for the Study of Obesity. Circulation 2009; 120(16):1640-5.

02. Metabolic Syndrome Institute 2006, The International Diabetes Federation proposes a new definition of the Metabolic Syndrome, Metabolic Syndrome Institute, Retrieved October 12, 2008, from http://www.metabolic-syndrome-institute.org/news/2006/200605-03

03. Dhanraj E, Bansali A, Jaggi S, Dutta P, Jain S, Tiwari P et al. Predictors of metabolic syndrome in Asian north Indians with newly Detected Type 2 Diabetes Mellitus. Indian journal Medical research 2009:129:506-514.

04. Enas EA,Mohan V,Deepa M, Farooq S, Pazhoor S, Chennikkara H.The metabolic

05. syndrome and dyslipidemia among Asian Indians: a population with high rates of diabetes and premature coronary artery disease. J Cardio Metabolic Syndrome 2007; 2(4):267-275.

06. Rahim MA, Khan AKA, Sayeed MA, Akhtar B, Nahar Q, Ali SMK et al. Metabolic syndrome in rural Bangladesh: Comparison of newly proposed IDF, modified ATP III and WHO criteria and their agreements. Diabetes \& Metabolic Syndrome: Clinical Research \& Reviews 2007; 1:.251-257.

07. Low S, Chin MC, Ma S, Heng D, Deurenberg-Yap M. Rationale for Redefining Obesity in Asians. Annals Academy of Medicine $2009 ; 38: 66-74$.

08. Dhanraj E, Bansali A, Jaggi S, Dutta P, Jain S, Tiwari P et al. Prevalence and predictor of metabolic syndrome in non- obese Asian Indians with newly Detected Type 2 Diabetes Mellitus. J Indian Med Association 2008;106:366-721. 
09. Haffner SM .The metabolic syndrome;inflammation,diabetes mellitus and cardiovascular Disease. Am J Cardiol 2006; 97:3A -11 A.

11. Mahadik SR, Deo SS, Mehtalia SD. Metabolic Syndrome In Non-Obese Asian Indian-An Urban-Rural comparison. Metabolic Syndrome and Related disorder 2007; 5(2): 142-152.

12. Janghorbani $M$, Amini,M. Metabolic Syndrome in type 2 Diabetes Mellitus in Isfahan, Iran: Prevalence and Risk factors. Metabolic Syndrome and Related disorders 2007; 5(3): 243-254.

13. Al-Shafaee MA, Ganguly SS, Bhargava K, Duttagupta KK.
Prevalence of Metabolic Syndrome among Prediabetic Omani Adults: A Preliminary Study.Metabolic Syndrome and related disorders 2008; 6(4): 275-279.

14. Malik M, Rajig SA. The Prevalence of the Metabolic Syndrome among the Multiethnic Population of the United Arab Enirates: A Report of a National Survey. Metabolic Syndrome and related disorders 2008; 6(3):177-186.

15. Li C, Ford ES.Definition of the Metabolic Syndrome: What's New and What Predicts Risk? Metabolic Syndrome and Related disorders 2006; 4(4): 237-251. 